Obstetrics and Gynaecology and with primary care assess patients with emotional problems during pregnancy or those who have experienced a termination of pregnancy, miscarriage, or a perinatal death. The team could advise about prevention of postnatal mental illness and assist other consultants with the management of their patients. Advice and support to primary health care workers, general practitioners, health visitors and social workers could be available more especially with regard to the assessment of parenting skills in patients with postnatal psychiatric illness - usually in collaboration with child psychiatrists. To establish links with self-help and other voluntary organisations, such as the Association for Postnatal Illness, New-Pin and Homestart, are particularly useful. Such a team would also provide a focus to facilitate education and research.

The future of these services is best guaranteed by a designated consultant psychiatrist with a special area of interest.

(c) Health Districts should ensure that the implementation of the White Paper Caring for Patients does not threaten those few services, both district based catchment area services and sub-regional inpatient facilities, that are currently running well and are a focus for service development, patient care and research. As the health care needs of a population will in future be met by contracts between purchasers and providers which involves costings, quality assurance and consumer satisfaction, the services for mentally ill mothers should be user friendly, accessible and consultant led, and so meet the standards set by the provider. Health district purchasing departments have a responsibility to meet significant health care needs, but the competitive market may threaten the viability of existing regional and district units.

(d) Health districts should ensure that facilities for data collection and cross-district clinical audit are available for a postnatal mental illness service which in smaller districts may require to be supra-district or sub-regional.

Approved by Council

March 1992

\section{References}

Brockington, I. F., Winokur, G. \& DeAn, C. (1982) Puerperal psychosis. In Motherhood and Mental Illness (eds I. F. Brockington \& R. Kumar) pp. 37-69. London: Academic Press.

DEAN, C. \& Kendell, R. E. (1981) The symptomatology of puerperal illnesses. British Journal of Psychiatry, 139, 128-133.

Dowlatashi, D. \& Paykel, E. S. (1990) Life events and social stress in puerperal psychoses: absence of effect. Psychological Medicine, 20, 655-662.

OATES, M. (1988) The development of an integrated community orientated service for severe postnatal mental illness. In Motherhood \& Mental Illness, Vol II (eds. R. Kumar \& I. Brockington), pp. 133-158. London: Academic Press.

Platz, C. \& Kendell, R. E. (1988) A matched-control follow-up and family study of puerperal psychoses. British Journal of Psychiatry, 153, 90-94.

Prettyman, R. J. \& Friedman, R. (1991) Care of women with puerperal psychiatric disorders in England and Wales. British Medical Journal, 302, 1345-1346.

A full list of references is available from the Publications Department at the College.

\title{
Working group on mental health information systems
}

The importance of information systems for clinical management, audit and resource management has been widely recognised by both the professions and management alike. While major advances in information technology have taken place in the acute hospital sector, a relative void exists within community services. Nevertheless over the last few years a number of developments have taken place which hold considerable promise for the information needs of community mental health services. In response to this void the Research Committee of the College has established a Working Group whose remit is to advise the College, and through it the Department, on the information needs of psychiatrists and the requirements of information systems that should support those needs.

Balancing the need for information is a need for communication. There is considerable risk that a myriad of unique solutions for clinicians, providers, purchasers and the Department will result in unnecessary duplication of effort and a major problem in communicating between users and management at all levels. Paradoxically the present void in information systems provides an opportunity to bring forward recommendations acceptable to clinicians and managers that will optimise communication between clinicians, within districts and across regions. The opportunities for research, audit, service evaluation and clinical 
practice are considerable, realisable only through harmonisation of the information collected, the method of collection and the systems employed.

Given the urgency in the present situation, the Working Group have agreed to report on their recommendations by the autumn of 1992 . The objectives include recommendations on:

(i) a minimum data set to meet information requirements at all levels, from clinical practice to the Department of Health

(ii) a data structure appropriate for the needs of clinical care and clinical audit

(iii) data comparability and data transfer

(iv) minimal technical specifications.
Membership of the group includes specialty representation and the College's Research Unit. Links have been established with the National Centre for Coding and Classification, the National Case Mix Office, Resource Management Site, the FACE Project, Conferences of Colleges Information Group. The purpose of the present note is to advise members of the College, and other interested groups, of the existence of the Working Group and its remit. Anyone requiring further information is invited to contact the Chairman through the College.

Professor Roy McClelland (Chairman)

\title{
Specialist Section for the Psychiatry of Old Age: Residential Conference Review
}

\author{
Cait Goddard, Consultant in the Psychiatry of Old Age, Bexley Hospital, \\ Kent DA5 2BW; and GianetTa Rands, Senior Registrar, The Maudsley Hospital, \\ London SE5 8AZ
}

The third annual residential conference of the Section was held in Jersey from 5 to 7 March 1992. One hundred and twenty delegates gathered to hear from a range of practitioners. Trainees had a high profile the policy of increasing to a third the proportion of higher trainees intending to be old age psychiatrists is beginning to bear fruit. A whole morning session was devoted to higher training issues ranging from the historical view of the relationship between old age psychiatry (OAP) and geriatrics, to a review of a successful higher training scheme, to innovative hopes for the future in the shape of Individual Performance Review (IPR) and an audit of audit. The senior registrar group's nationwide survey of current higher training experiences was presented.

The Section's support of its trainees was further evident in the fact that three-quarters of the short papers and poster presentations were trainee projects. A wide range of subjects were covered from the psychological sequelae of the Lockerbie disaster in elderly people, to NMR imaging of eggs and brains, to the evolution of the DV system.

The Section adheres to a traditional large group format as its main vehicle for communication. Such large groups have disadvantages - silencing the timid and less experienced and at times not silencing the more aggressively confrontational members. It was noticeable in formal sessions that generational groups had different communication styles - senior members questioning and applauding senior members, trainees listening to and constructively commenting on the work of their contemporaries. At times newer consultants intervened when difficult issues threatened conflict between the generations.

Plentiful free time was scheduled by the organisers and this, as always, was one of the most positive aspects of the residential conference. It was most constructively filled with informal conversation, networking, gossiping and relaxing. Cross-generational communications occurred more easily at such times. As membership of the section increases, itself a reflection of success, it may be that alternative structures for formal sessions could be considered to preserve the benefits of small groups. These could include workshops, working parties and special interest subgroups such as trainees, new consultants, clinical directors and research groups, some of which already exist. These changes could be seen at subsequent residential and quarterly meetings.

A great deal of effort was put into making everyone welcome and the organisation was of the usual high standard we've come to expect of Jean Wales. Our Jersey hosts put on a good show, demonstrating some of the quirks of Jersey life, the problems of organising services on a small island and offering a guided tour of their service. 